\title{
STUDENTS' CONCEPTION OF LEARNING AND LEARNING BEHAVIOR FROM MULTIPLE-GOALS PERSPECTIVE
}

\author{
Mai Yokoyama and Kazuhisa Miwa \\ Nagoya University, Japan
}

\begin{abstract}
The purpose of this study was to examine conception of learning and learning behavior for each goal orientation type from the multiple-goals perspective and to clarify the characteristics of each type. Questionnaire surveys were conducted with fourth-year undergraduate students, and responses for 340 students were analyzed. We created four types, namely, <Low-goals>, <High-goals>, <High-Performance-Avoidance-goals>, and <High-Learning-goals>, and each type of conception of learning and learning behavior were examined. The results suggested that conception of learning differs by type. <High-goals> tended to have multiple conceptions of learning, <High-Learning-goals> tended to have Active conception of learning, and <Low-goals type> and <High-Performance-Avoidance-goals> tended to have Passive conception of learning.
\end{abstract}

\section{KEYWORDS}

Multiple-Goals Perspective, Conception of Learning, Learning Behavior

\section{INTRODUCTION}

\subsection{Conception of Learning}

Conception of learning is defined as learners' ideas and beliefs about learning. Research on conception of learning began in the 1970s, primarily in Europe (e.g., Säljö, 1979; Van Rossum \& Schenk, 1984). Säljö (1979) observed following five conceptions of learning: an increase in knowledge, memorization, acquisition of facts and procedures that could be retained and/or used in practice, abstraction of meaning, and an interpretative process to understand reality. He defined the former three as the passive accumulation of knowledge, obtained externally as the passive accumulation of knowledge obtained from the outside, and the latter two as the active acquisition, interpretation, and application of knowledge obtained internally. Marton et al. (1993, 1996) described the following six categories: an increase in knowledge, memorizing and reproducing, applying, understanding, seeing something in a different way or as, and changing as a person. They organized the former three conceptions as the surface conception of learning and the latter three as the deep conception of learning. In subsequent studies on conception of learning, the former is "quantitative conception of learning" or "fragmental conception of learning," and the latter is "qualitative conception of learning" and "cohesive conception of learning" (e.g., Dart et al., 2000; Ellis et al., 2008); thus, conception of learning has been perceived as dualistic concepts.

Purdie et al. (1996) observed that a duty, the development of social competence, and a process not bound by time or place could be added to the six conceptions of learning presented by Marton et al. (1993). Takayama (2000) observed the following nine conceptions of learning based on data from a survey completed by Japanese university students: memorizing, an active investigation, lifelong learning, natural acquisition, an increase in knowledge, growing and improving, applying, acquiring and repetition, and a duty. Learning as a process not bound by time or place (Purdie et al. 1996) and learning through natural acquisition (Takayama 2000) are new conceptions of learning incompatible with the dualistic concepts by Marton et al. $(1993,1996)$. 
Based on the classification of conception of learning in the literature, conception of learning can be organized into the following three categories (Table 1): (1) Active conception of learning: Learning is for changing and growing oneself and/or learning should be performed actively using thoughts; (2) Passive conception of learning: Learning is forced by others and/or learning is the passive processing of learning content; (3) Experiential conception of learning: Learning occurs in everyday experiences.

Table 1. Three categories of conception of learning

\begin{tabular}{|c|c|c|c|c|}
\hline & & Marton et al. (1993) & Purdie et al. (1996) & Takayama (2000) \\
\hline (1) & $\begin{array}{l}\text { Active } \\
\text { conception of } \\
\text { learning }\end{array}$ & $\begin{array}{l}\text { Understanding } \\
\text { Seeing something different way or as } \\
\text { Changing as a person }\end{array}$ & The development of social competence & $\begin{array}{l}\text { Applying } \\
\text { Acquiring and repetition } \\
\text { Growing and improving } \\
\text { Lifelong learning } \\
\text { An active investigation }\end{array}$ \\
\hline (3) & $\begin{array}{l}\text { Experiential } \\
\text { conception of } \\
\text { learning }\end{array}$ & & A process not bound by time or place & Natural acquisition \\
\hline
\end{tabular}

Van Rossum and Schenk (1984) conducted an empirical study on learning behavior in relation to reading materials. Students who perceived learning as memorizing adopted a superficial learning behavior in which they only read a summary, whereas students who perceived learning as the abstraction of meaning or an interpretative process aimed to understand the reality of adopted deep learning behavior and read the sentences while processing the relationships between the paragraphs. Dart et al. (2000) suggested that students who had conceptions such as personal fulfillment and as a process were not bound by time and were more likely to use deep approaches to learning compared with students who had conceptions, such as an increase in knowledge, who were more likely to rely on superficial approaches. Takayama (2002) suggested that learning as an active investigation, learning as growing and improving, and learning as acquiring and repetition have positive effects on deep learning behavior such as associating new learning with prior knowledge or confirming an individual's understanding; by contrast, learning as a duty has a negative effect. Considering the relationship between the results of these studies and the three aforementioned conceptions of learning, the Active conception of learning tends to promote adaptive learning behavior, and the Passive conception of learning suppresses adaptive learning behavior.

Purdie \& Hattie (2002) and Alamdarloo et al. (2013) have examined the relationship between the number of conceptions of learning and academic performance. They demonstrated that the higher the number of conceptions of learning that students have (i.e., the more multiple conceptions of learning that students have), the higher their academic achievement.

\subsection{Goal Orientation}

Goal-achievement theory (Dweck 1986), which accounts for differences in learning behavior in terms of each students' goals as they execute tasks, classifies such goals into two categories: learning and performance goals. The purpose of the former is to acquire new knowledge and skills through challenging activities, whereas that of the latter is to seek positive and avoid negative evaluations. Students with learning goals tend to select challenging tasks and persevere even when they encounter failure, regardless of their confidence in their abilities. Performance-oriented appear similar to students with the learning orientation, provided they are confident in their abilities; however, if they lack confidence, they are less likely to persevere to completion. Elliot and Dweck's (1988) findings support the latter statement. Ames and Archer (1987, 1988) demonstrated that learning goals have a positive effect on academic achievement and endogenous motivation; learning goals are generally considered superior for attaining learning achievement.

Elliot and Harackiewicz (1996) divided performance goals into performance-approach goals, in which a student attempts to outperform others, and performance-avoidance goals, or attempting to avoid performing 
worse than others. Elliot and Church (1997) and Rawsthorne and Elliot (1999), among others, have demonstrated that performance-approach goals lead to positive effects on endogenous motivation and academic performance, but performance-avoidance goals have negative effects, demonstrating the importance of distinguishing between the approach and avoidance utilities.

\subsection{Multiple-Goals Perspective}

According to the multiple-goals perspective (e.g., Elliot, 1999; Harackiewicz et al., 2002; Pintrich, 2000), a student has multiple goals, rather than a single goal. Printrich (2000) and Daniels et al. (2008) have classified students into the following four types according to the combination of learning goal orientation and performance goal orientation: (1) High-goals (i.e., high learning goal orientation and performance goal orientation), (2) High-Learning-goals (i.e., high learning goal orientation), (3) Low-goals (i.e., low learning goal orientation and performance goal orientation), and (4) High-Performance-goals (i.e., high performance goal orientation).

Printrich (2000), Daniels et al. (2008), and Valle et al. (2003) have demonstrated that students classified as having Low-goals and High-Performance-goals have a similar tendency to have negative perceptions (e.g., "boredom" with schools and classes) and do not use adaptive learning behavior, whereas the High-goals and High-Learning-goals students have a similar tendency to have positive perceptions (e.g., "enjoyment" regarding schools and classes) and use adaptive learning behavior. High-goals students have been shown to have the best academic performance among the four types (Daniels et al., 2008; Valle et al., 2003). Considering that these goal orientation types differ in school and class perceptions, learning behavior, and academic achievement, differences are likely to be observed in conception of learning, depending on the student's combination of goal orientation.

This study proceeded based on the following hypotheses derived from findings in the literature. First, Low-goals and High-Performance-goals students who tend to recognize activities in schools and classes negatively would have Passive conception of learning. High-Learning-goals students who tend to recognize activities in schools and classes positively would have Active conception of learning. Considering the results in the literature that students with multiple conceptions of learning perform well (1.1), High-goals students who tend to recognize schools and classes positively and show good academic performance would have multiple conceptions of learning including Active conception of learning.

Regarding learning behavior, referring to the results of Printrich (2000), Daniels et al. (2008), and Valle et al. (2003), High-goals and High-Learning-goals students would show adaptive learning behavior, whereas their Low-goals and High-Performance-goals counterparts would not.

\subsection{Purpose}

The purpose of this study is to verify the hypotheses on conception of learning and learning behavior for each goal orientation type and clarify the characteristics of each type.

We investigated graduation thesis research conducted at a university, on which most students work regardless of their faculties or specialties. The ratio of graduation studies as compulsory subjects at universities in Japan is as high as $80 \%$, indicating that approximately $90 \%$ of students work on graduation studies (Association of Private University in Japan, 2011). Students were required to set their themes and objectives, consider methods for the objectives, conduct literature research or experiments according to those methods, and summarize the results. Many opportunities were available for students to make judgments. Hence, we hypothesized that how the students actively engaged in this type of learning may be greatly influenced by the students' learning orientation.

\section{METHOD}

\subsection{Subjects and Procedures}

The survey was conducted with fourth-year students from the School of Integrated Arts and Sciences at a Japanese public university in February 2018 and February 2019. The participants answered questionnaires during the presentation session of their graduation thesis. The data of 340 students $(2018: 161,2019: 179)$ were analyzed. 


\subsection{Measures}

The participants were asked to indicate their agreement or disagreement with each item in the questionnaires on a 5-point Likert scale.

\section{Goal Orientation}

The questionnaire comprised 18 items from Yokoyama and Miwa (2018) translated from the Achievement Goal Scale developed by Elliot and Church (1997).

\section{Conception of Learning}

The questionnaire comprised 24 items from Yokoyama and Miwa (2018) partially modified from Takayama's (2002) scales.

\section{Learning Behavior}

The questionnaire comprised 8 items from Yokoyama and Miwa (2018) modified from scales by Mitsunami (2010) and Hatano \& Mizoue (2013). The items were modified to measure students' learning behavior in the context of undertaking graduation work.

\section{RESULTS AND DISCUSSION}

\subsection{Structure of the Scales}

\section{Goal Orientation}

As a result of factor analysis (principal factor with promax rotation), three factors consistent with Yokoyama $\&$ Miwa (2018) emerged: Learning Goal (4 items; $\alpha=$.75), Performance-Approach Goal (3 items; $\alpha=.72$ ), and Performance-Avoidance Goal (5 items; $\alpha=.81$ ). An average value of the items was regarded as the respective value of each factor.

\section{Conception of Learning}

As a result of factor analysis (principal factor with promax rotation), four factors consistent with Yokoyama \& Miwa (2018) emerged: Autonomous Development (5 items; $\alpha=.88$ ), Duty and Memorizing (5 items; $\alpha=.84$ ), Growing as a Person (4 items; $\alpha=.78$ ), and Effort (4 items; $\alpha=.79$ ). An average value of the items was regarded as the respective value of each factor.

\section{Learning Behavior}

As a result of factor analysis (principal factor with promax rotation), one factor consistent with Yokoyama $\&$ Miwa (2018) emerged ( 8 items; $\alpha=.80$ ). An average value of the eight items was regarded as the learning behavior variable.

\subsection{Goal Orientation Type}

First, cluster analysis (Ward 's method, square Euclidean distance) was performed using the three goal orientation variables. With reference to the goal orientation types of Printrich (2000) and Daniels et al. (2008), we adopted four clusters and created four goal orientation types (Figure 1). These four types are consistent with the classification of Printrich (2000) and Daniels et al. (2008). Type $1(\mathrm{~N}=93)$ corresponds to the Low-goals type because all three goal orientations are lower than average. Type $2(\mathrm{~N}=83)$ corresponds to the High-goals type because all three goal orientations are higher than average. Type $3(\mathrm{~N}=132)$ corresponds to the High-Performance-goals type because performance-avoidance goal orientation is higher than average. Type $4(\mathrm{~N}=32)$ corresponds to High-Leaning-goals type because learning goal orientation is higher than average. Hereinafter, Types 1 to 4 are referred to as <Low-goals> <High-goals> <High-Performance-Avoidance-goals> $<$ High-Learning-goals>. 


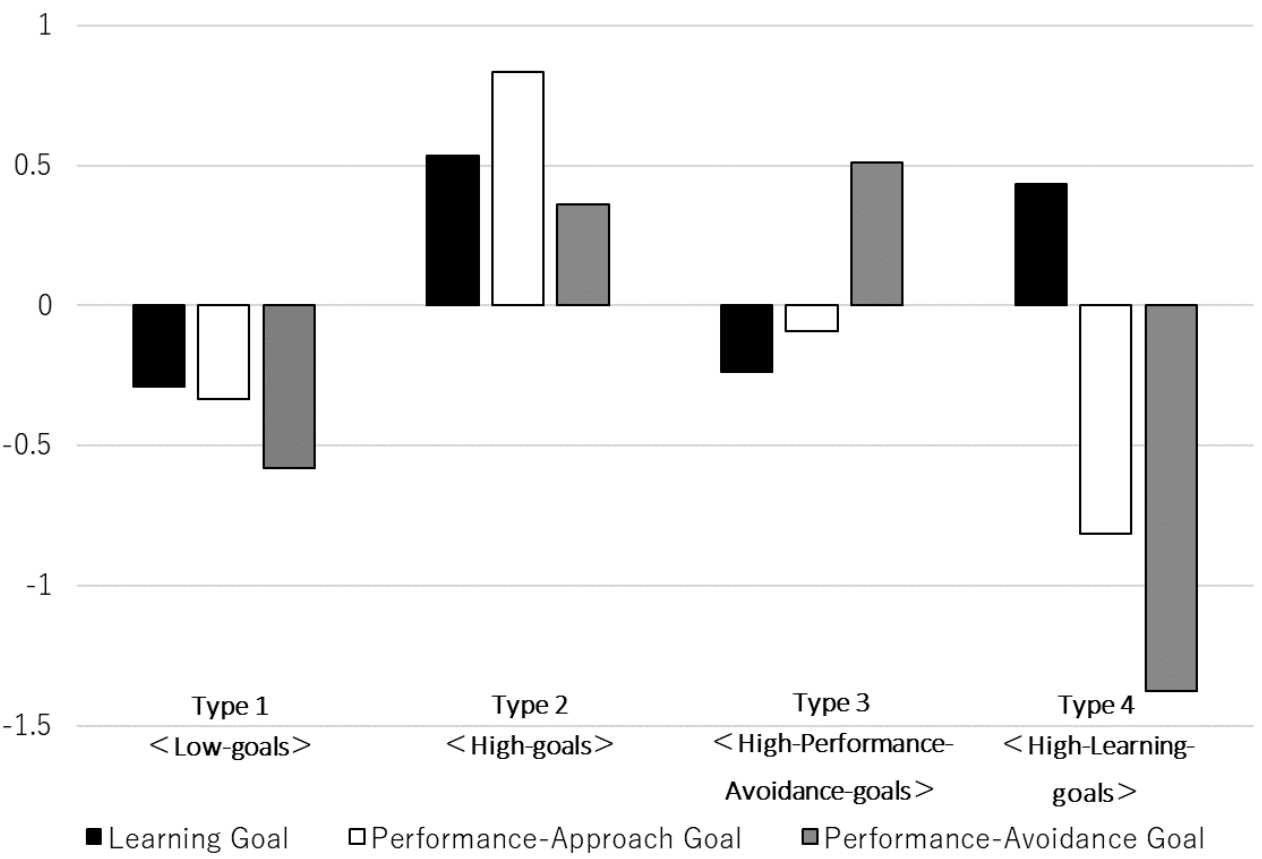

Figure 1. Goal orientation types

\subsection{Conception of Learning and Learning Behavior for each Goal Orientation Type}

To examine the difference in conception of learning and learning behavior between each goal orientation type, a one-way ANOVA was performed with goal orientation type as the explanatory variable and each conception of learning and learning behavior as the explained variables. In all cases, the goal orientation type factor was significant; hence, multiple comparisons (Turkey method, 5\% level) were performed. The results are presented in Table 2.

Table 2. One-way ANOVA Results

\begin{tabular}{lccccccc}
\hline & & $\begin{array}{c}\text { Type 1 } \\
\text { Low-goals }\end{array}$ & $\begin{array}{c}\text { Type 2 } \\
\text { High-goals }\end{array}$ & $\begin{array}{c}\text { Type 3 } \\
\text { High-Performance- } \\
\text { Avoidance-goals }\end{array}$ & $\begin{array}{c}\text { Type 4 } \\
\text { High- } \\
\text { Learning-goals }\end{array}$ & $\begin{array}{c}F \text { value } \\
(d f=3,336)\end{array}$ & $\begin{array}{c}\text { Multiple } \\
\text { comparisons }\end{array}$ \\
\hline Autonomous & $M$ & 4.18 & 4.51 & 4.10 & 4.53 & 10.65 & $1,3<2,4$ \\
Development & $(S D)$ & $(0.66)$ & $(0.42)$ & $(0.67)$ & $(0.46)$ & $* * *$ & $1,3<1,2,3$ \\
Duty and & $M$ & 2.28 & 2.46 & 2.45 & 1.59 & 14.40 & $4<1,3<2$ \\
Memorizing & $(S D)$ & $(0.71)$ & $(0.81)$ & $(0.67)$ & $(0.45)$ & $* * *$ & $1,3.59$ \\
Growing as a & $M$ & 3.59 & 4.08 & 3.71 & 3.59 & 10.59 & $1,3,4<2$ \\
Person & $(S D)$ & $(0.72)$ & $(0.51)$ & $(0.63)$ & $(0.58)$ & $* * *$ & $1<2$ \\
Effort & $M$ & 3.93 & 4.29 & 4.01 & 3.73 & 6.67 & 1,3 \\
Learning & $(S D)$ & $(0.74)$ & $(0.57)$ & $(0.63)$ & $(0.88)$ & $* * *$ & \\
Behavior & $M$ & 3.59 & 3.88 & 3.69 & 3.82 & 4.70 & $1<2$ \\
\hline
\end{tabular}

<Low-goals> and <High-Performance-Avoidance-goals> had lower Autonomous Development scores than <High-goals> and <High-Learning-goals> and had a higher Duty and Memorizing scores than $<$ High-Learning-goals>. These results support the hypothesis of this study: these two types would have Passive 
conception of learning. Daniels (2008) demonstrated that these two types tend to perceive classes as "boredom" rather than "enjoyment." As observed from these conceptions of learning, the fundamental reason why students perceive their classes negatively may be that they perceive learning as being forced by others rather than an autonomous process.

<High-goals> had a higher Autonomous Development score than <Low-goals> and $<$ High-Performance-Avoidance-goals>, had a higher Duty and Memorizing score than <High-Learning-goals> , and a higher Growing as a Person score and Effort score than the other three types. In other words, the scores of all four conceptions of learning were high, suggesting that they have multiple conceptions of learning including Active conception of learning, as hypothesized in this study. <High-Learning-goals> had a higher Autonomous Development score than <Low-goals> and <High-Performance-Avoidance-goals> and had a lower Duty and Memorizing score than the other three types. This result partially supports the hypothesis of this study: High-Learning goals students would have Active conception of learning. In studies with the multiple-goals perspective, <High-goals> and <High-Learning-goals> have had similar trends in learning perception and behavior (e.g., Printrich, 2000; Daniels, 2008). The results of this study indicate that these two types of students differ. An inference is that <High-goals> students learn from multiple perspectives, have a wide range of adaptability, and apply learning behaviors according to the situation. By contrast, an inference is that <High-Learning-goals> students that apply learning behaviors based on their belief that learning is not forced by others but is performed autonomously.

<High-Goals> had a higher learning behavior score than <Low-goals>. This result is consistent with that of Daniels (2008) for academic achievement. This result partially supports the hypothesis that High-goals and High-Learning-goals students would show adaptive learning behavior, whereas Low-goals and High-Performance-goals students would not. Ueki (2002) described an ideal learner as having multiple conceptions of learning and using appropriate learning behaviors according to the situation. <High-goals> students have high scores in all four conceptions of learning and learning behavior; therefore, they tend to have multiple conceptions of learning and use adaptive learning behavior. This type of student is similar to the ideal learner proposed by Ueki (2002).

\section{CONCLUSION}

In this study, we created four goal orientation types based on goal orientation combinations, namely, <Low-goals>, <High-goals>, <High-Performance-Avoidance-goals>, and <High-Learning-goals>, and examined conception of learning and learning behavior of each type. The results suggest that conception of learning and learning behaviors differ by goal orientation type. Studies have demonstrated differences in the perception of classes and learning behavior on the basis of goal orientation type, and this study is significant because it suggests differences in learning beliefs are an impetus. In addition, although the recognition and learning behavior of <High-goals> and <High-Learning-goals> have been shown to be similar in previous studies, we demonstrated that these two types of conception of learning differ, and clarified the characteristics of each type. In this respect, this study added new empirical findings.

The limitations of this study are as follows. First, we measured students' goal orientation, conception of learning, and learning behavior by a single time point survey. However, a preferable method is to perform follow-up based on surveys at multiple time points to examine conception of learning and learning behavior from a goal orientation perspective, namely, a measurement of goal orientation before starting graduation research and a conception of learning and learning behavior at the end of graduation research. Second, we used self-evaluation by students as a measure of learning behavior. Barnett \& Hixon (1997) and Klein (1998) confirmed that self-evaluation by students is reliable; however, to further guarantee objectivity, we should have added a more objective viewpoint such as an evaluation by teachers.

\section{ACKNOWLEDGMENT}

This work was partially supported by JSPS KAKENHI Grant Number $18 \mathrm{H} 05320$. 


\section{REFERENCES}

Alamdarloo, G., Moradi, S. \& Dehshiri, G. (2013). The Relationship between Students' Conceptions of Learning and Their Academic Achievement. Psychology, Vol. 4,pp 44-49.

Ames, C., \& Archer, J. (1987). Mothers' beliefs about the role of ability and effort in school learning. Journal of Educational Psychology, Vol. 79, pp 409-414.

Ames, C., \& Archer, J. (1988). Achievement goals in the classroom: Students' learning strategies and motivation process. Journal of Educational Psychology, Vol. 80, pp 260-267.

Association of Private University in Japan (2011). Survey report on the reform status of the second bachelor course education and recognition of the current situation

Barnet, J.E., \& Hixon, J.E. (1997). Effects of Grade Level and Subject on Student Test Score Predictions. Journal of Educational Research, Vol.90, pp 170-175.

Daniels, L. M., Haynes, T. L., Stupnisky, R. H., Perry, R. P., Newall, N. E., \& Pekrun, R. (2008). Individual differences in achievement goals: A longitudinal study of cognitive, emotional, and achievement outcomes. Contemporary Educational Psychology, Vol. 33, pp 584-608.

Dart, B.C., Burnett, P.C., Purdie, N., Boulton-Lewis, G., Campbell, J., \& Smith, D. (2000). Students' conceptions of learning, the classroom environment, and approaches to learning. The Journal of Educational Research, Vol. 93, pp 262-270.

Dweck, C. S. (1986). Motivational processes affecting learning. American Psychologist, Vol. 41, pp 1040-1048.

Elliot, A. J. (1999). Approach and avoidance motivation and achievement goals. Educational Psychologist, Vol. 34, pp 169-189.

Elliot, A. J., \& Church, M. A. (1997). A hierarchical model of approach and avoidance achievement motivation. Journal of Personality and Social Psychology, Vol. 72, pp 218-232.

Elliot, A. J., \& Harackiewicz, J. M. (1996). Approach and avoidance achievement goals and intrinsic motivation: A mediational analysis. Journal of Personality and Social Psychology, Vol. 70, pp 461-475.

Elliott, E. S., \& Dweck, C. S. (1988). Goals: An approach to motivation and achievement. Journal of Personality and Social Psychology, Vol. 54, pp 5-12.

Ellis, R. A., Goodyear, P., Calvo, R. A., \& Prosser, M. (2008). Engineering students' conceptions of and approaches to learning through discussions in face-to-face and online contexts. Learning and Instruction, Vol. 18, pp 267-282.

Hatano, K., \& Mizokami, S. (2013). The examination of student' type based on active class attitude and learning time in university students. Japan Journal of Educational Technology, Vol. 37, pp 13-21.

Harackiewicz, J. M., Barron, K. E., Pintrich, P. R., Elliot, A. J., \& Thrash, T. M. (2002). Revision of achievement goal theory: Necessary and illuminating. Journal of Educational Psychology, Vol. 94, pp 638-645.

Klein, P. A.(1998). Self-assessment in mathematics as a placement/advising tool. Research and Teaching in Developmental, Vol.15, pp 117-128.

Marton, F., Dall'Alba, G., \& Beaty, E. (1993). Conceptions of learning. International Journal of Educational Research, Vol. 19, pp 227-300.

Marton, F., Wen, Q., \& Nagle, A. (1996). Views on learning in different cultures. Comparing patterns in China and Uruguay. Anales de Psicologia. Vol. 12, pp 123-132.

Mitsunami, M. (2010). Influence of achievement motive and goal orientation on learning behavior: Different in cognitive strategies. Japanese Journal of Educational Psychology, No. 58, 348-360.

Pintrich, P. R. (2000). Multiple goals, multiple pathways: The role of goal orientation in learning and achievement. Journal of Educational Psychology, Vol. 92, pp 544-555.

Purdie, N., \& Hattie, J. (2002). Assessing Students' Conceptions of Learning. Australian Journal of Educational and Developmental Psychology, Vol. 2, pp 17-32.

Purdie, N., Hattie, J., \& Douglas, G. (1996). Student conceptions of learning and their use of self-regulated learning strategies: A cross-cultural comparison. Journal of Educational Psychology, Vol. 88, pp 87-100.

Rawsthorne, L. J., \& Elliot, A, J. (1999) Achievement goals and intrinsic motivation: A meta-analytic review. Personality and Social Psychology Review, Vol. 3, pp 326-344.

Säljö, R. (1979). Learning in the learner's perspective. I. Some common-sense conceptions. Reports from the Istitute of Education, No. 76, Sweden: University of Göteborg.

Takayama, S. (2000). Characteristics and structure of student conception of learning. Memoirs of the Faculty of Education, Shimane University, Vol. 34, pp 1-10.

Takayama, S. (2002). The relationship between learning conception, it's determinants and learning strategies. Memoirs of the Faculty of Education, Shimane University, Vol. 37, pp 19-26. 
Ueki, E. (2002). Structure of high-school students' beliefs about learning. Japanese Journal of Educational Psychology, Vol. 50, pp 301-310.

Valle, A., Cabanach, R.G., Núñez, J.C., González-Pienda, J., Rodríguez, S.y Piñeiro, I. (2003). Multiple goals, motivation and academic learning. British Journal of Educational Psychology, Vol. 73, pp 71-87.

Van Rossum, E. J., \& Schenk, S. M. (1984). The relationship between learning conception, study strategy and learning outcome. British Journal of Educational Psychology, Vol. 54, pp 73-83.

Yokoyama, M., \& Miwa, K. (2018). Relationship between Goal Orientation, Conception of Learning and Learning Behavior. Proceedings of 15 th international conference of cognition and exploratory learning in digital age (CELDA 2018), pp.233-240.

\section{APPENDIX}

\section{Goal Orientation}

- Learning Goal

I hope my knowledge is broader and deeper when I am done with classes. / I want to learn as much as possible from my classes. / I prefer course material that really challenges me so I can learn new things. / I prefer course material that arouses my curiosity, even if difficult to learn.

-Performance-Approach Goal

I strive to demonstrate my ability in relation to others. / I am motivated by the opportunity to outperform my peers.

Outperforming other students is important to me.

-Performance-Avoidance Goal

I worry about getting a bad grade. / I often think to myself, "What if I do badly?" / My fear of performing badly often motivates me. / I just want to avoid a bad grade. / I am afraid that if I ask my teachers a "dumb" question, they might think I am not very smart.

\section{Conception of Learning}

-Autonomous Development

Learning is something we continue to do as long as we live. / Learning continues after I become a member of society.

Learning is something that continues throughout life. / Learning is attempting to understand what you are deeply interested in. / Learning is actively exploring your interests.

- Duty and Memorizing

Learning is forced without the freedom. / Learning is forced by parents or teachers. / Learning is being forced to do things that you do not want to do. / Learning is accurately memorizing the content of materials. / Learning is memorizing the textbook content at a desk.

- Growing as a Person

Learning means living a life like a human being. / Learning involves human beings' forming a spiritual core. / Learning is not accumulating knowledge but forming an attitude. / Learning means absorbing a wide range of knowledge.

$\cdot$ Effort

Learning is what you acquire with effort. / Learning takes much time and effort. / Learning is necessary to become a member of society. / Learning means absorbing more knowledge.

\section{Learning Behavior}

I tried to improve the quality of my graduation thesis as much as possible. / Although it was difficult, I worked on it without giving up. / I studied what I did not know, or I asked my teacher and my friends about it. / I set goals and plans. / I often tried to read and understand the contents. I was prepared to respond to any questions in the presentation. / I worked on the research merely to earn credit. / I often got bored quickly and quit. 